\title{
THE EFFECTS OF RADIATION DAMAGE AND IMPURITIES ON VOID DYNAMICS IN SILICON*
}

S. E. Donnelly ${ }^{1}$, V. M. Vishnyakov ${ }^{1}$, R. C. Birtcher ${ }^{2}$, and G. Carter ${ }^{1}$

\author{
${ }^{1}$ Joule Physics Laboratory \\ University of Salford \\ Manchester M5 4WT \\ United Kingdom \\ ${ }^{2}$ Materials Science Division \\ Argonne National Laboratory \\ 9700 S. Cass Ave. \\ Argonne, IL 60439
}

September 2000

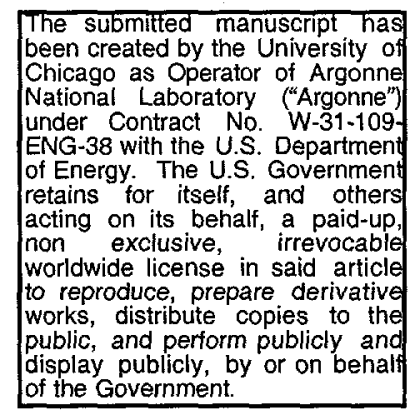

Submitted to the International Conference on Ion Beam Modification of Materials, CanelaRio Grande do Sul, Brazil, on September 3-8, 2000.

*Work supported by the UK Engineering and Physical Science Research Council (EPSRC) under grant number GR/M33242. 


\section{DISCLAIMER}

This report was prepared as an account of work sponsored by an agency of the United States Government. Neither the United States Government nor any agency thereof, nor any of their employees, make any warranty, express or implied, or assumes any legal liability or responsibility for the accuracy, completeness, or usefulness of any information, apparatus, product, or process disclosed, or represents that its use would not infringe privately owned rights. Reference herein to any specific commercial product, process, or service by trade name, trademark, manufacturer, or otherwise does not necessarily constitute or imply its endorsement, recommendation, or favoring by the United States Government or any agency thereof. The views and opinions of authors expressed herein do not necessarily state or reflect those of the United States Government or any agency thereof. 


\section{DISCLAIMER}

Portions of this document may be illegible in electronic image products. Images are produced from the best available original document. 
The Effects of Radiation Damage and Impurities

on Void Dynamics in Silicon

\section{NOV $0 \& 2000$ \\ OSTI}

S E Donnelly, V M Vishnyakov, * R C Birtcher† and G Carter*
*Joule Physics Laboratory, University of Salford, Manchester M5 4WT, UK
† Materials Science Division, Argonne National Laboratory, Argonne IL 60439, USA

\begin{abstract}
Transmission electron microscopy (TEM) has been used to study the effects of implanted oxygen or carbon on the dynamics of cavity growth in silicon. The cavities are produced by implantation with helium ions followed by annealing to convert small He-filled bubbles into large empty voids. In an attempt to separate the effect of radiation damage, inevitably introduced when implanting the impurities, from the effect of the mere presence of the impurities in the silicon, we have also investigated the effects of self-ion damage on cavity growth. Both impurities and self ion damage significantly inhibit void growth. In addition, hot stage TEM has been used to elucidate the processes responsible for cavity growth in an attempt to understand the way in which both impurities and radiation damage are able to modify those processes. Cavity growth is seen to be due to Ostwald ripening and coalescence in the early stages with some sporadic, rapid motion of large bubbles leading to coalescence at higher temperatures. Our research indicates that void dynamics in silicon are quite different from those in metallic systems.
\end{abstract}

PACS Nos.: 61.72.Ff, 61.82.Fk, 61.72Qq, 61.72-y

Key words: voids, bubbles, helium, silicon, gettering

Contact author: S E Donnelly Joule Physics Laboratory, University of Salford, Manchester M5 4WT, UK Email: s.e.donnelly@salford.ac.uk Phone: +44 1612955392

Fax: $\quad$ +441612955336 


\section{Introduction}

Impurities are unintentionally introduced into silicon at all production stages of microelectronic devices. Although bulk impurity concentrations are generally very low, impurities tend to accumulate in active regions of devices leading to a local modification of both electrical and mechanical properties which may result in faulty operation. To avoid this problem it is necessary to produce safe gettering sites where impurities will preferentially accumulate and be stably bound during both device production and operation. Significant efforts will be needed to lower the concentration of transition metal impurities to levels required in future devices [1].

There are many ways to produce gettering sites in silicon and binding energies for different metal impurities to the different sites vary considerably [2]. Recently it has been shown that voids created by implantation of hydrogen and helium and subsequent annealing [3] could be effective gettering sites for some metallic impurities [4-10]. It is believed that this process is driven by chemisorption of the impurities on the internal walls of cavities [11]. The monovalent metals $\mathrm{Cu}$ and $\mathrm{Au}$ react with the single dangling orbitals on the cavity wall, whereas high-valence metals such as $\mathrm{Fe}$ and Co mostly form silicides but are, up to certain concentrations, also effectively gettered by voids $[9,10$, 12]. In general, the binding energy to voids for many metals lies in the range 1.5 to $2.2 \mathrm{eV}$ [11]. (Note that the energies referred to here are not desorption energies but the energy for re-solution of the impurity into the silicon matrix).

The surface of a large facetted void in $\mathrm{Si}$ is generally observed to consist of $\{111\}$ and $\{100\}$ facets, with essentially no $\{110\}$ and $\{311\}$ facets and without sharp corners [13]. Mössbauer spectroscopy has shown that there are two distinguishable gettering sites on a void surface in silicon [9]. One is characterised by a high binding energy and is thought to be associated with an atomic step; the second has a lower binding energy and represents a site on a flat facet. Other work has also shown that there is a clear correlation between gettering efficiency and void size [14] (or strictly, mean size, as voids generally form with a range of sizes that depends on implantation and 
annealing conditions). In particular, cavities with a mean diameter of $12 \mathrm{~nm}$ were observed to have a binding energy $0.13 \mathrm{eV}$ higher than cavities with a mean diameter of $31 \mathrm{~nm}$.

The aim of the current project is to produce "tailored" void distributions with the highest possible binding energy for transition metal impurities. The work, to date, has thus been concerned with developing a suitable recipe for enabling small voids to survive high temperature anneals. In addition we have focused on developing a fundamental understanding of the processes responsible for void growth in silicon to enable us to understand the inhibitory processes.

In general, small helium-filled cavities (bubbles) with diameters up to $3.5 \mathrm{~nm}$ are observed in silicon implanted at room temperature (prior to any annealing treatment) [3]. The dynamics of helium release and cavity coarsening during high temperature annealing has been investigated by a number of authors $[3,6,15,16]$. The mean void diameter is observed to increase with anneal temperature and, by analogy with metals [17], it is believed that bubbles and voids migrate by internal surface diffusion. During annealing, helium (unlike its behaviour in metals) is able to leave the cavities and diffuse through the lattice to be released at the surface. Collisions between cavities during migration results in coalescence leading to growth. Inhibition of cavity growth has been observed following oxygen implantation and is believed to be due to suppression of surface diffusion and cavity migration [18]. However, from the point of view of gettering, oxygen may not be an ideal impurity to use to impede void growth as it has also been found to cause the ejection of $\mathrm{Au}$ from $\mathrm{H}$-formed cavities during annealing [19],

In this paper we firstly present results from experiments using cross-sectional TEM on the effects of oxygen, carbon and self-ion radiation damage on cavity growth in bulk silicon during annealing. Secondly we present work carried out in order to shed some light on cavity growth mechanism in an attempt to understand the way in which the presence of impurities or self-ion induced radiation damage in the vicinity of the growing cavities can inhibit their growth. This work consists of in-situ 
TEM annealing experiments on thin silicon specimens containing small helium bubbles in order to follow the evolution of the bubbles into large facetted voids. Note that in this paper the word "cavity" is used to refer to both a bubble, which contains helium, and a void, which does not.

\section{Experimental}

Specimens used in this study, apart from those used for in-situ annealing, were cut from SEMI standard, double-side polished $300 \mu \mathrm{m}$ thick, p-type (boron, up to 4 to $10 \mathrm{ohm} \mathrm{cm}$ ) $\{100\}$ floating zone (Fz) silicon wafers. The oxygen and carbon content, as specified by the supplier, are less than $2 \times 10^{16}$ atoms $/ \mathrm{cm}^{3}$. Specimens used for the in-situ annealing were single-side polished $400 \mu \mathrm{m}$ thick p-type (boron, 80 to $160 \mathrm{ohm} \mathrm{cm}$ ) $\{110\}$ Czochralski $(\mathrm{Cz})$ silicon wafers.

For the cross sectional work, ion implantations were carried out under a vacuum of $10^{-4} \mathrm{~Pa}$ with hydrocarbon contamination minimised by the use of a liquid-nitrogen cooled baffle around the specimen stage. Samples were tilted $7^{\circ}$ from normal incidence to avoid channeling and were mechanically scanned to give a uniform ion fluence across the specimen. He ion energy was $10 \mathrm{keV}$ and the He ion flux was kept constant at $3 \times 10^{13} \mathrm{ion} / \mathrm{cm}^{2} / \mathrm{sec}$ for all specimens. The implantation regimes are tabulated in Table 1 . Note that multiple energies were used for $\mathrm{C}$ and self-ion irradiations in order to produce a relatively uniform impurity/damage distributions over the range of the helium. Temperature during all implantations was within a few degrees of room temperature. Bulk samples were annealed in a quartz tube furnace under a vacuum of $3 \times 10^{-5} \mathrm{~Pa}$ with a liquid nitrogen trap to minimise hydrocarbon contamination. Cross sectional samples were prepared for TEM by microcleavage $[20,21]$ and were examined in a JEOL $200 \mathrm{CX}$ microscope operating at 200 $\mathrm{keV}$.

Specimens for the in situ annealing experiments were prepared by diamond core drilling $3 \mathrm{~mm}$ disks from the wafers. These were then mechanically ground to a thickness of $200 \mu \mathrm{m}$ before being dimpled and electrochemically jet thinned to perforation in a non-acid etch. To ensure that the bulk 
of the implanted He stopped in the pre-thinned specimens, He was implanted at $5 \mathrm{keVinto}$ these specimens. Implantations were carried out at room temperature, under a residual vacuum of $10^{-6}$ Pa using a flux of $1 \times 10^{13}$ ion/ $/ \mathrm{cm}^{2} / \mathrm{sec}$. All results reported in this paper (in situ and ex-situ) are for a helium dose of $5 \times 10^{16}$ ions $/ \mathrm{cm}^{2}$. In situ annealing experiments were carried out in a double tilt heating holder in a Hitachi H-9000 TEM operating at $300 \mathrm{keV}$. Note that a $300 \mathrm{keV}$ electron can transfer up to $30 \mathrm{eV}$ to a Si atom (a $200 \mathrm{keV}$ electron can transfer up to $19 \mathrm{eV}$ ) and thus may displace an atom off its lattice site; however, we are not aware of any effects caused by the electron beam in the experiments reported here. All images in the present communication (on both microscopes) were recorded with the electron beam close (within $4^{\circ}$ ) to a $\langle 110\rangle$ pole and with the objective lens underfocused slightly (typically by $1000 \mathrm{~nm}$ ) in order to optimise void contrast. Images were recorded either on photographic film or on S-VHS video tape, the latter by means of a Gatan 622 camera and image intensification system with a frame rate of 30 per second. Images were subsequently digitised after passing the video signal from tape through a running 4-frame averager.

\section{Results}

The void distribution in a helium-implanted sample annealed at $900^{\circ} \mathrm{C}$ for $30 \mathrm{~min}$ is shown in Fig.1. Most voids lie between 60 and $160 \mathrm{~nm}$ below the surface, with a low concentration of small voids extending to the surface. Ion range calculations using the Monte Carlo code TRIM96 [22] (also shown in the figure) indicate that voids do not form over the entire helium range distribution. This is almost certainly due to the fact that He bubbles do not form below some critical He concentration even after annealing [23]. The He concentration in the region beyond the void distribution in Fig. 1 is presumably below this critical value. This is in contrast to the behaviour of helium bubbles in metals in which regions of lower helium concentration would generally contain a lower concentration of smaller bubbles after annealing (i.e. no critical concentration for bubble formation). Measurements on both as-implanted samples and samples annealed at lower temperatures (to be published elsewhere) also show that the interface between the voids and the 
underlying silicon is always very sharply defined and does not noticeably change its position during annealing and void coarsening.

\section{Growth Inhibition}

The effect of pre-implantation with either oxygen or carbon ions (see Table 1 for details) on the void size distribution following anneals to different temperatures is shown in Fig 2 a), b) and c) for anneals to $900^{\circ} \mathrm{C}$. The most marked changes in the size distribution occur following implantation with $\mathrm{O}$ ions, however significant modifications are also observed following pre-implantation with $\mathrm{C}$ ions. Both pre-implantation treatments result in much larger numbers of small bubbles surviving to high temperatures. In the case of carbon pre-implantation, however, many larger voids are also present.

Ion implantation inevitably creates radiation damage. In order to determine whether damage plays a role in the growth inhibition observed for both $\mathrm{C}$ and $\mathrm{O}$ pre-implantations, we have self ionirradiated the specimen with different Si energies both before and after He implantation. In all cases, this resulted in a significant reduction in the mean void size after anneal. An example of this effect is given in Fig. $2 \mathrm{~d}$ (see Table 1 for details of pre-implantation). The damage has resulted in a decrease in the mean void radius by a factor of two. The oxygen pre-implantation, however, yielded a factor of 4 reduction in mean radius, despite the fact that the radiation damage produced by oxygen was less than that produced by the self-ion irradiation. The presence of oxygen, therefore, and not merely the lattice damage caused by its implantation, reduces void growth. An estimate of the total internal void surface area leads to the conclusion that at most there should be only around $10 \%$ of a monolayer coverage of the void surface by the oxygen if all the implanted oxygen finds its way to the internal surfaces.

The situation is less clear in the case of carbon. The size distributions in Fig. 3 suggest that carbon has affected only a fraction of the He bubbles and that a large fraction coarsened as in the case of 
pure He implantation. However, this effect is not due to partial overlap of the carbon and helium range profiles as the carbon was implanted in a flat distribution spanning the helium distribution. The co-existence of small and large cavities does not reduce the usefulness of the carbon implantation as far as the gettering of transition metal impurities is concerned. Provided that some significant fraction of the voids are small they will still provide more stable traps for transition metals and this will be unaffected by the presence of larger voids. The surface area available in small voids will of course be smaller in the carbon case, than in the case of oxygen but for the small concentrations of impurities likely to be present in actual devices this may not be a problem. In view of the fact that oxygen has been observed to be inimical to the gettering of Au by voids [19], implantation of carbon ions to inhibit void growth may be a more suitable treatment than oxygen.

The estimated number of displaced silicon atoms due to the relatively small silicon fluence used to produce the distribution in Figure 2d, is approximately $10 \%$ of that due to the subsequent helium irradiation. An increase of $10 \%$ in the helium fluence would thus be expected to result in an inhibition of void growth if the nature of the defects following irradiation with silicon and helium were the same. This does not occur, indicating that damage resulting from the silicon irradiation must be different in nature from that resulting from the helium implantation itself. At room temperature, silicon irradiation can result in amorphisation of the implanted region, whereas a 10 $\mathrm{keV}$ helium implantation at room temperature will not result in amorphisation . Eaglesham and coworkers [24] have shown that the so called "plus one" model provides a reasonably accurate description of defects remaining after silicon implantation. On annealing to successively higher temperatures, disorder, probably in the form of small interstitial-rich zones (which may be amorphous) in the as implanted material is converted firstly to rod-like $<311>$ defects which are interstitial in nature or into interstitial dislocation loops for higher dose implantations. The number of interstitials remaining in these defects after annealing corresponds essentially to one silicon interstitial (or more accurately 1.5) for each impinging silicon ion. The high temperature release of interstitials from such defects is thought to be the origin of transient enhanced diffusion. In the 
present experiments, we estimate our as implanted helium bubble concentration to be approximately $5 \times 10^{13}$ bubbles $/ \mathrm{cm}^{2}$ compared with approximately $1.5 \times 10^{15} \mathrm{Si} / \mathrm{cm}^{2}$ interstitials remaining in defects according to the "plus one" model. On interstitial release from the defects, at a temperature when voids are growing, there are thus approximately $30 \mathrm{Si}$ interstitials per initial bubble. As the interstitials diffuse through the specimen and trap in the cavities they would be expected to greatly reduce cavity sizes giving rise to the overall reduction in void volume observed after annealing.

Although no similar detailed analysis has been carried out of damage resulting from helium irradiation, helium and other light ions, with their more dilute collision cascades certainly do not produce small amorphous zones at room temperature. The relatively high concentration of "stored" interstitials may not result from the light ion damage so that "transient enhanced" void annihilation does not take place as a result.

\section{Observations of cavity growth}

The cavity size distributions shown in Fig 2, indicate clearly that cavity growth on annealing to high temperature can be significantly modified by the presence of impurities or radiation damage in the implanted area. To understand why this occurs requires a general understanding of cavity growth processes in silicon.

An equilibrium bubble is generally a neutral sink for vacancies and interstitials but in metals, thermal bubble growth can occur when defects such as dislocations act as preferential sinks for interstitials, allowing more vacancies than interstitials to be absorbed by a bubble. Growth will also occur by coalescence when growing bubbles come into contact with each other - a process which is greatly enhanced at higher temperatures by bubble motion. Thermally induced, random migration of cavities occurs (in metals) as a consequence of both bulk and surface diffusion processes. The activation energy for self diffusion in Si has reecently been measured to be $4.75 \mathrm{eV}$ [25]. With such 
a high activation energy, the contribution of bulk self diffusion to bubble motion in Si will be negligible at the temperatures used in this work. As far as surface diffusion processes are concerned there is some disagreement in the literature regarding the appropriate activation energy. STM measurements yield vacancy dimer diffusion energies of $1.7 \mathrm{eV} \mathrm{[26]} \mathrm{and} 2.1 \mathrm{eV}$ [27] for surface diffusion on a (100) surface and somewhat lower values for the (111) surface. Motion of a cavity will be limited by the facet with the least surface mobility.

If the appropriate activation energy for surface diffusion, $E_{S}$, and the jump attempt rate $v_{O}$ are known then the resulting rate of cavity motion during the time to capture a video frame $(1 / 30 \mathrm{sec})$ is given by [28]:

$$
2(\lambda / \mathrm{N}) \sqrt{30} v_{\mathrm{O}} \exp \left(-\mathrm{E}_{\mathrm{S}} / \mathrm{kT}\right)
$$

where $\lambda$ is the atomic jump distance, $\mathrm{N}$ is the number of vacancies in the cavity and $\mathrm{k}$ is Boltzmann's constant . On the basis of equation 1, the rate of cavity movement (projected on to a plane) versus cavity radius is shown in Fig. 3. (A value for $v_{0}$ of $10^{13} \mathrm{~s}^{-1}$ has been used in both cases). Note that the rate of movement refers to the distance moved by the cavity along its random path (as measured by a frame by frame analysis of video recordings).

For the lower activation energy of $1.7 \mathrm{eV}, 1 \mathrm{~nm}$ cavities would be expected to migrate significantly at temperatures of $700^{\circ} \mathrm{C}$ and above. For instance a 10 minute anneal at $700^{\circ} \mathrm{C}$ would be expected to result in a motion along the path of $900 \mathrm{~nm}$, and this rises to $2400 \mathrm{~nm}$ for a 10 minute anneal at $800^{\circ} \mathrm{C}$. For the higher activation energy, the figures are approximately a factor of 5 lower but clearly the the smallest cavities would be expected to be mobile at temperatures of $700^{\circ} \mathrm{C}$ and above. For larger cavities (<3nm in radius, say) and assuming the lower activation energy, some mobility is to be expected at $700^{\circ} \mathrm{C}$ (less than $1 \AA / \mathrm{s}$ ) but at $800^{\circ} \mathrm{C}$ a $3 \mathrm{~nm}$ cavity might be expected to migrate a few tens of nanometres in the course of a ten minute anneal. For an activation energy of 2.1 this would be reduced by approximately an order of magnitude. 
Helium bubbles formed by implantation of pre-thinned Si were annealed in-situ in the TEM. Images recorded on video tape were subsequently examined frame by frame. Contrary to expectations, motion of small bubbles was in general not observed. Instead, bubbles on average were observed to increase in size, sometimes coalescing when their larger size resulted in contact with a neighbouring bubble. Bubbles were also observed both to disappear and form (without motion) during a slow temperature ramp from $663^{\circ} \mathrm{C}$ to $694^{\circ} \mathrm{C}$ over a period of 6 minutes. This is illustrated in Fig. 4 where video frames recorded 6 minutes apart are shown. The bubble just to the left of the "X" in Fig, 4b is not visible in Fig. 4a and was seen simple to "fade in" on the video recording. On the other hand the bubble just to the left of the "Y" in Fig. 4a was observed to "fade out" on the video recording and is not present in Fig. 4b. In general, small bubbles seem to form when very small patches of background contrast appear to coalesce - this can be seen in the case of the bubble which appeared between frames just left of the "Z" on Fig. 4b and which seemed to result from the aggregation of three small patches of contrast.

In general small bubbles may thus either appear or disappear, but on average bubbles increase in size and decrease in number during this phase of the growth process implying that Ostwald ripening is taking place.

At $800^{\circ} \mathrm{C}$, if surface diffusion with an activation energy as low as $1.7 \mathrm{eV}$ is taking place then significant (Brownian) motion of small bubbles is to be expected. In fact during several annealing experiments to temperatures as high as $850^{\circ} \mathrm{C}$ we observed no such motion of small bubbles. However, larger cavities were observed occasionally and sporadically to migrate rapidly over distances up to $50 \mathrm{~nm}$ before coalescing on contact with other cavities. An example of this is illustrated in figure 5 where the cavity (radius 3.5.nm) marked " $\mathrm{A}$ " moves and coalesces to form the large cavity in the top right-hand corner of Figure $5 \mathrm{~d}$. The temperature during this sequence is constant at $840^{\circ} \mathrm{C}$. Analysis of videotaped recordings of many such events reveals that the motion is jerky, with the cavity moving in steps of up to $5 \mathrm{~nm}$. During each step the cavity moves at a rate of 
5-10 $/$ s which is somewhat faster than predicted by Fig. 3 for the lower activated process $(\approx 1 \AA / s)$.

Sporadic motion is difficult to understand, particularly given the apparent lack of mobility of small bubbles in general which would imply higher values for the activation energy for surface diffusion than those used in Fig. 3. At the temperature at which the sporadic motion of larger bubbles is observed, extended defects are also annealing. For instance, $\{311\}$ defects may be converting into Frank loops, and loops may be dissociating. We speculate that the cavity motion may be associated with such processes taking place in the vicinity of the cavity.We have also observed identical behaviour for Ne bubbles in $\mathrm{Si}$ in the same temperature range. Further research is underway ont this topic.

\section{Conclusions}

Growth of He bubbles in Si into voids is inhibited by the implantation of carbon or oxygen or by self-ion damage in the region of the implanted helium from implanted Si or impurities. The effect is greatest for oxygen. The inhibition due to radiation damage can be understood in terms of interaction of the cavities with silicon self-interstitials. The observed inhibition due to the presence of impurities, however, cannot be due to the reduction of cavity motion caused by the presence of impurities in the cavity surface, as has been suggested, as motion does not play any role in the early stages of cavity growth. The activation energy for surface diffusion on cavity surfaces would thus appear to be somewhat higher than the values deduced from STM measurements on flat UHV external surfaces. Bubble growth appears to be due primarily to Ostwald ripening. We speculate, that the impurities $\mathrm{O}$ and $\mathrm{C}$ may in fact impede the diffusion of helium and vacancy clusters and that this may inhibit the ripening process. Sporadic, rapid motion has been observed to result in coalescence and growth for a small number of cavities at high temperatures. This latter effect is not understood but may be associated with the behaviour of nearby extended defects. It is perhaps also 
worth noting that voids in addition to being traps for impurities are also traps for silicon self interstitials and could perhaps be used to limit transient enhanced diffusion.

\section{Acknowledgements}

This work is supported by the UK Engineering and Physical Sciences Research Council (EPSRC) under grant number GR/M33242. We thank Chester Faunce, Ed Ryan, Loren Funk, Tony McCormick, Pete Baldo, Stan Ockers and Bernie Kestel for technical assistance and one of us (SED) acknowledges funding from the Materials Science Division at Argonne National Laboratory which enabled the collaborative visit during which part of this work was performed. 


\section{References}

1. The National Technology Roadmap for Semiconductors (Semiconductor Industry Assoc., San Jose, CA, 1994), pp. 110-131.

2. K.Graff. Metal Impurities in Silicon-Device Fabrication (Springer-Verlag, Berlin, 1995)

3. C.C. Griffioen, J.H. Evans, P.C. de Jong and A. van Veen. Nucl. Instr. \& Meth. B. 27, 417 (1987).

4. S.M. Myers, D.M. Bishop, D.M. Follstaedt, H.J. Stein and W.R. Wampler. Mat. Res. Soc. Symp. Proc. 283, 549(1993).

5. J.Wong-Leung, C.E. Ascheron, M. Petravic, R.G. Elliman and J.S. Williams. Appl. Phys. Lett. $66(10), 1231(1995)$.

6. A. Van Veen, H. Schut, R.A. Hakvoort, A. Fedorov and K.T. Westerduin. Mat. Res. Soc. Symp. Proc. 373, 499(1995).

7. M.H.F. Overwijk, J. Politiek, R.C.M. de Kruif, P.C. Zalm. Nucl. Inst. and Meth. B 96, 257(1995).

8. V. Raineri, A. Battaglia and E.Rimini. Nucl. Instr. \& Meth. B. 96, 249(1995).

9. W. Deweerd, T. Barancira, S. Bukshpan, S. Denuynck, G. Langouche, K. Milants, R. Moons, J. Verheyden and H. Pattyn. Phys. Rev. B, 53, 16637(1996).

10. R.A. Yankov, J.R. Kaschny, P.F.P. Fichtner, A .Mucklich, U. Kreisig and W. Skopura. Microelectronic Eng. 36, 129(1997).

11. G.A. Petersen, S.M. Myers, D.M. Follstaedt. Nucl. Instr. \& Meth. B. 127-128, 301(1997).

12. W. Deweerd, R. Moons, K. Milants, J. Verheyden, G. Langouche, H. Pattyn. Nucl. Instr. \& Meth. B. 127-128, 307(1997).

13. D.J. Eaglesham, A.E. White, L.C. Feldman, N. Moriya and D.C. Jacobson. Phys. Rev. Lett. 70, 11, 1643(1993).

14. F. Schiettekatte, C. Wintgens and S. Roorda. Appl. Phys. Lett. 74, 1857(1999).

15. V. Raineri. Solid State Phenom. 57-58, 43(1997).

16. D.M. Follstaedt, S.M. Myers, G.A. Petersen, J.W. Medernach, J. Elec. Mat. 25 (1996) 151

17. R.N. Wright and C.DeW. van Siclen. J. Nuc. Mat. 206, 87(1993).

18. J.H. Evans, A. van Veen and C.C. Griffioen. Nucl. Instr. \& Meth. B. 28, 360(1987).

19. J.S. Williams, M.J. Conway, J. Wong-Leung, P.N.K. Deenapanray, P. Petravic, R.A. Brown, D.J. Eaglesham and D.C. Jacobson. Appl. Phys. Lett. 75, 2424(1999).

20. J.P. McCaffrey. Microscopy Res. And Tech. 36, 372(1997).

21. S. Suder, C. A. Faunce and S. E. Donnelly. Thin Solid Films 304, 157 (1997) 
22. J. F. Ziegler, J. P. Biersack, and U. Littmark. The Stopping and Ranges of Ions in Solids, (Pergamon Press, New York, 1985).

23. P. F. P. Fitchner, J. R. Kaschny, R. A. Yankov. A. Mücklich, U. Kreissig, Appl. Phys. Lett.70 (1997) 732

24. D.J. Eaglesham, P.A. Stolk, H.-J. Gossmann, T.E. Haynes, J.M. Poate. Nucl. Inst. and Meth. B 106, 191(1995).

25. H. Bracht, E.E. Haller, R Clark-Phelps, Phys. Rev. Lett. 81 (1998) 393.

26. N.Kitamura, M.G. Lagally, M.B. Webb, Phys. Rev. Lett. 71 (1993) 2082

27. A. Ichimiya, Y. Tanaka, K. Hayashi, Surf. Sci. 386 (1997) 182

28. C.W. Allen, R.C. Birtcher, S.E. Donnelly, K. Furuya, N. Ishikawa, M. Song, Appl. Phys. Lett. 74 (1999) 2611 
Table 1 Energy and doses used for helium implantations and various pre-implantations. Multiple implants of $\mathrm{C}$ and $\mathrm{Si}$ were used to produce flat-topped impurity/damage profiles.

\begin{tabular}{llc}
\hline & Energy (keV) & Dose (ions $\left./ \mathbf{c m}^{2}\right)$ \\
\hline Helium & 10 & $5.0 \times 10^{16}$ \\
\hline Oxygen & 45 & $5.0 \times 10^{14}$ \\
\hline Carbon & 50 & $1.0 \times 10^{15}$ \\
& 10 & $3.3 \times 10^{14}$ \\
& 5 & $6.6 \times 10^{14}$ \\
\hline Silicon & 135 & $1.0 \times 10^{15}$ \\
(self-ion) & 25 & $3.3 \times 10^{14}$ \\
& & \\
\hline
\end{tabular}




\section{Figure Captions}

Fig.1 Comparision between range and damage distribution for $10 \mathrm{keV}$ helium implanted into silicon calculated using TRIM [22] with the void distribution seen in cross-sectional TEM following a 30 minute anneal to $900^{\circ} \mathrm{C}$.

Fig. 2. Void size distributions observed following different pre-implantations and a 30 minute anneal at $900^{\circ} \mathrm{C}$. See Table 1 for details of implantations.

Fig. 3. Calculated rate of movement of cavities due to surface diffusion as a function of radius for different temperatures and for two activation energies for surface diffusion.

Fig. 4. Cavity evolution during a slow temperature ramp: a) $\mathrm{T}=663^{\circ} \mathrm{C} \mathrm{b}$ ) image taken 6 minutes later with $\mathrm{T}=694^{\circ} \mathrm{C}$. Scale marker represents $10 \mathrm{~nm}$. See text for details.

Fig. 5. Motion of a large bubble (marked "X") at $840^{\circ} \mathrm{C}$. a) $\left.t=0 \mathrm{~s} ; \mathrm{b}\right) \mathrm{t}=12 \mathrm{~s}$; $\left.\mathrm{c}\right) \mathrm{t}=16 \mathrm{~s}$; d) $\mathrm{t}=27 \mathrm{~s}$. Scale marker indicates $10 \mathrm{~nm}$. 

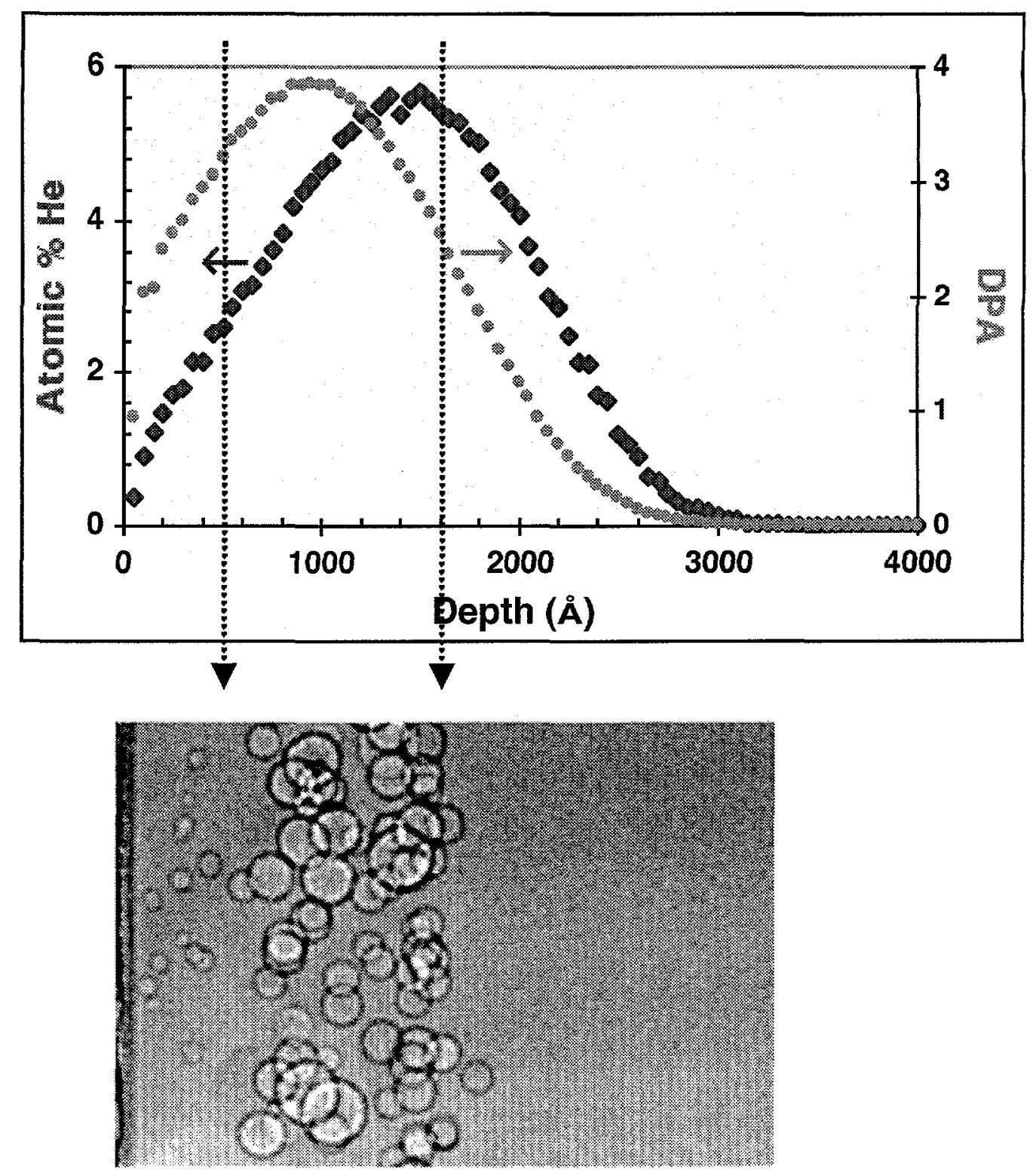

$2 i g 1$ 
$\%$ in Size Range

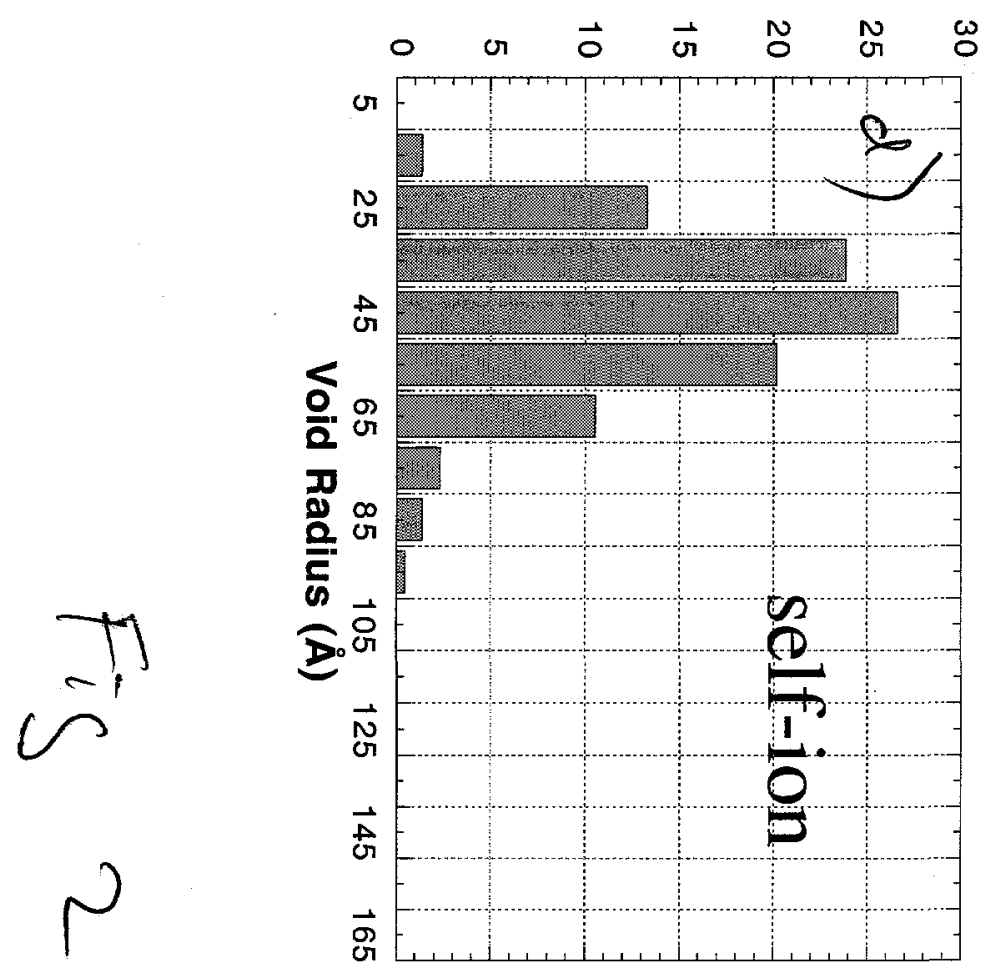

$\%$ in Size Range

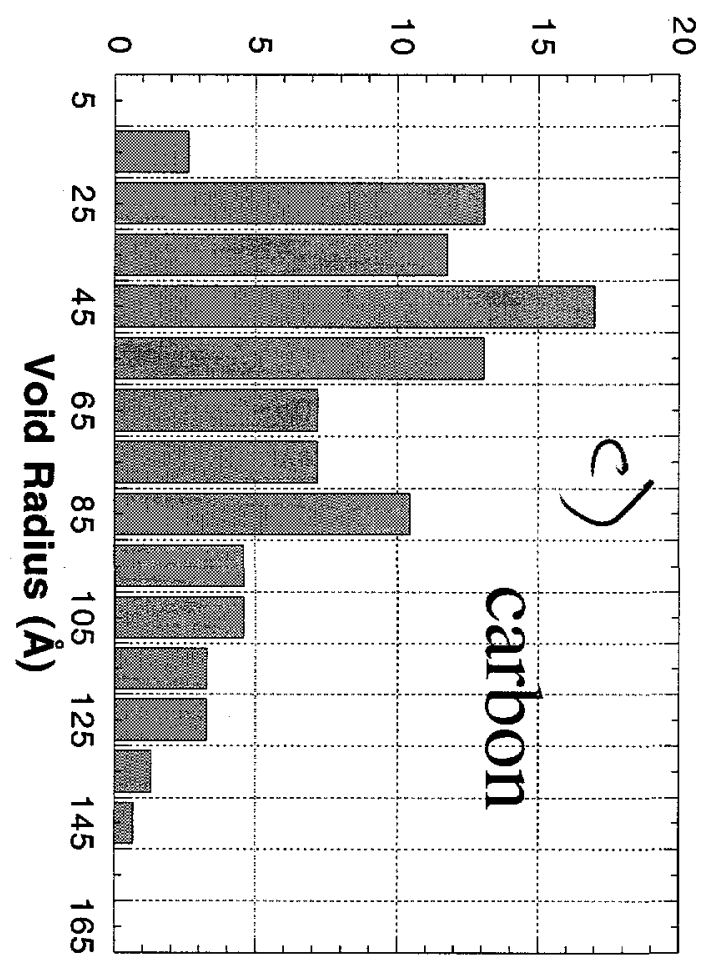

\% in Size Range

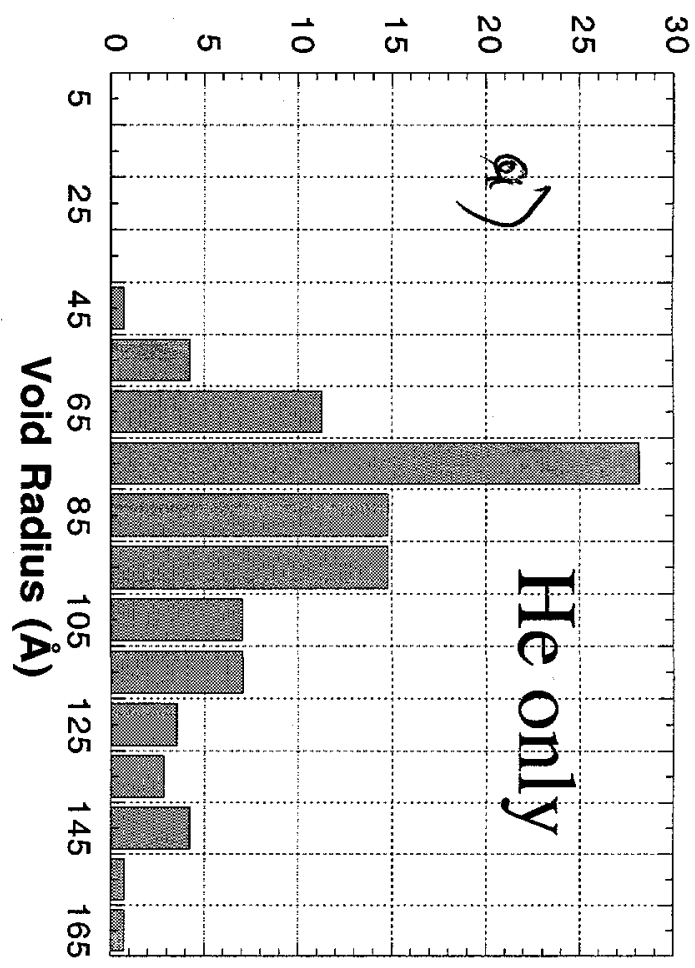

\section{$\%$ in Size Range}

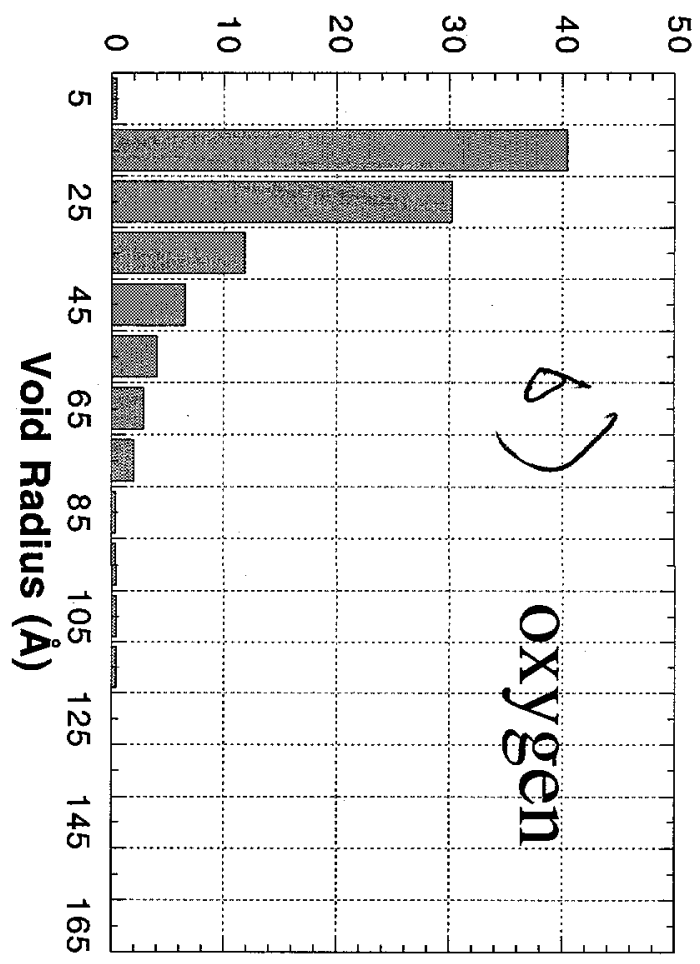


a)

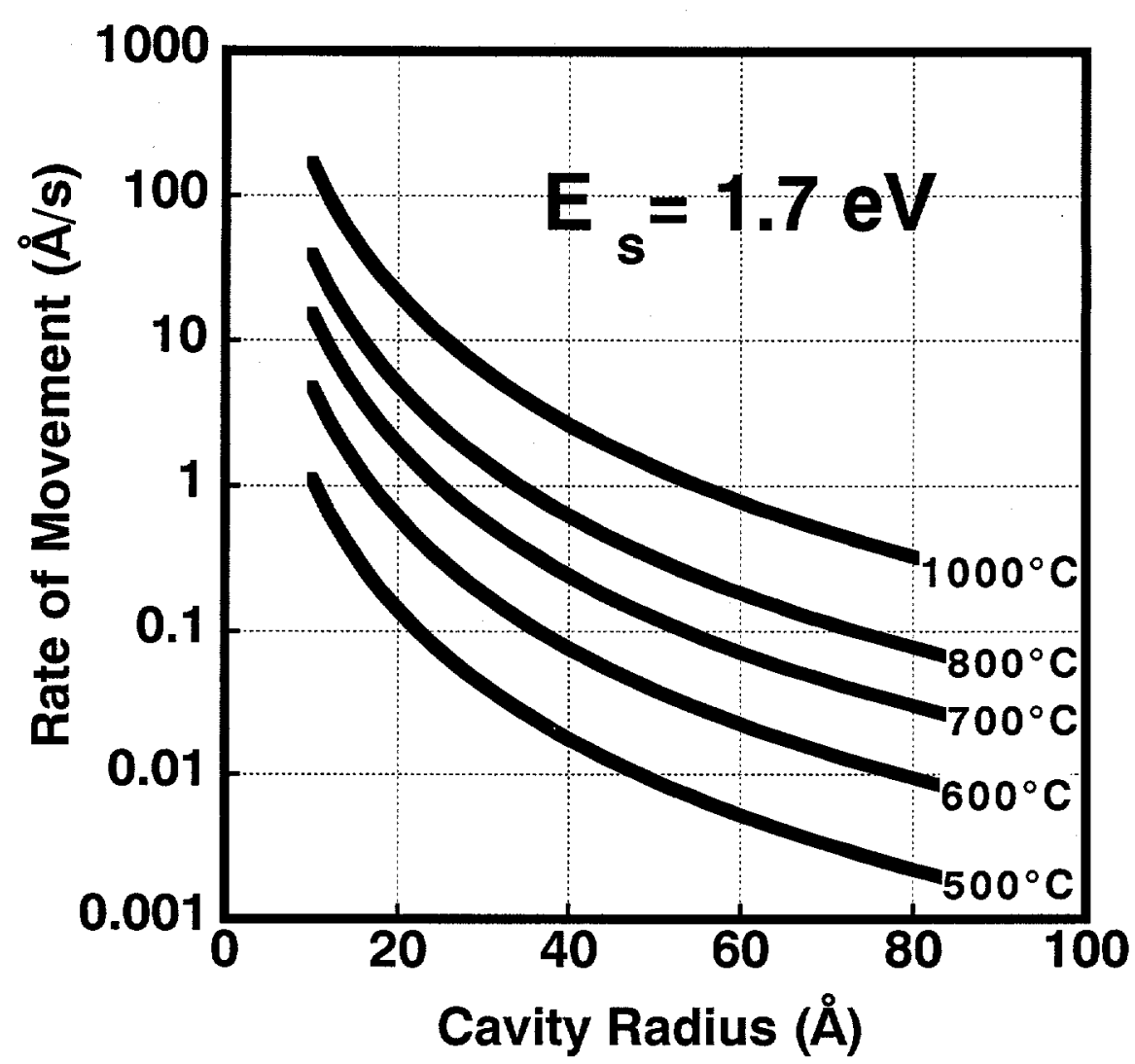

6)

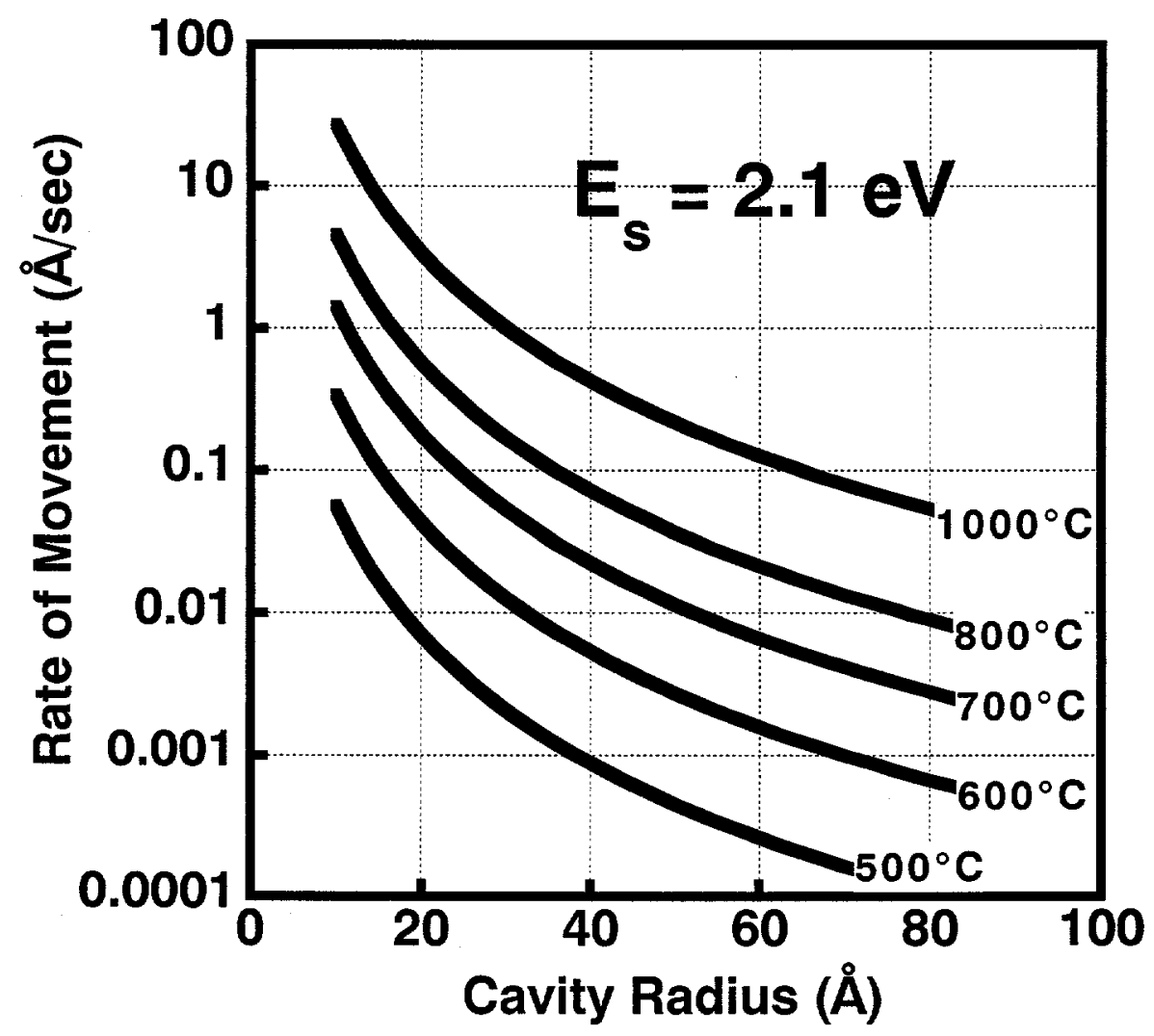

Fis 3 

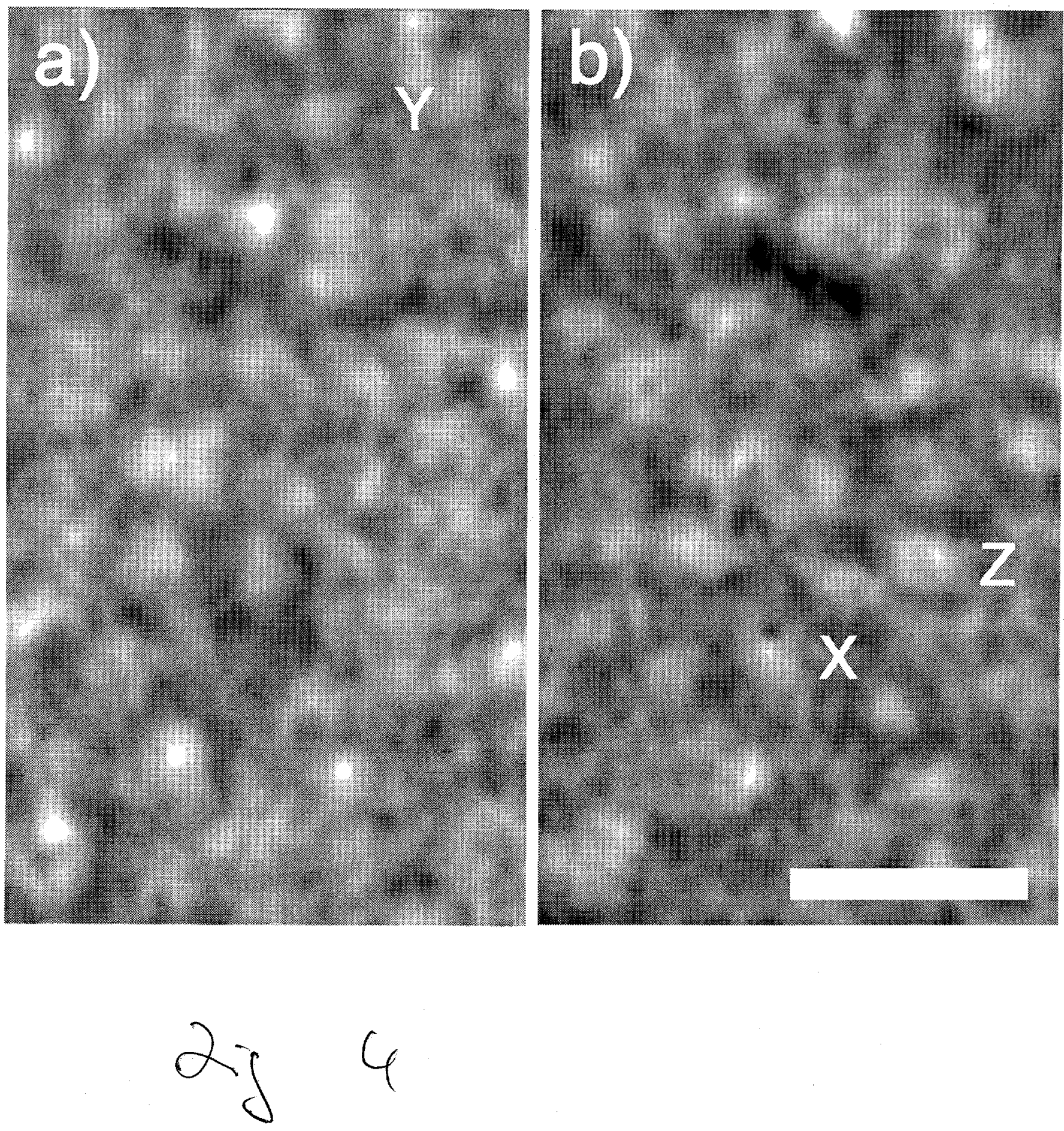

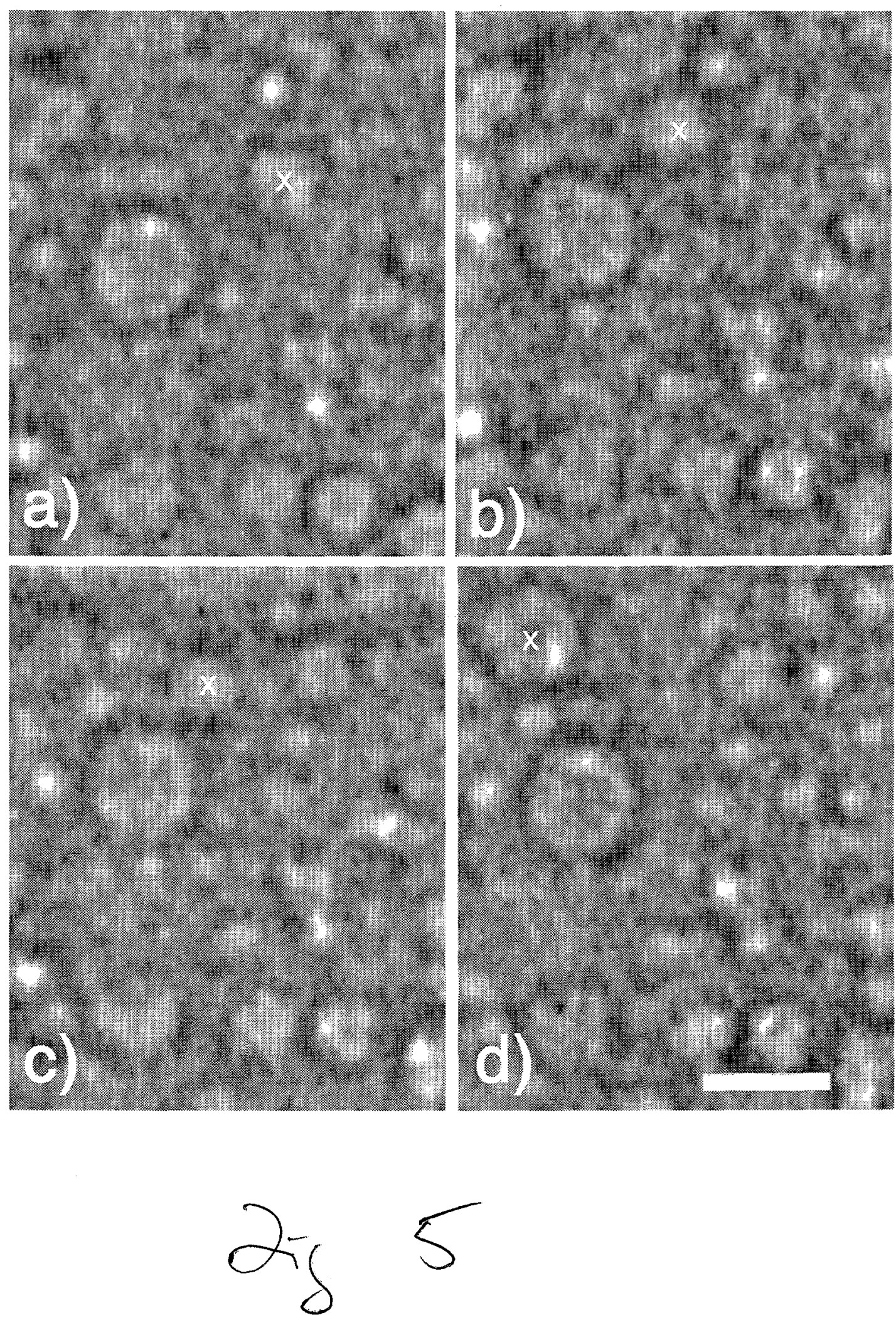